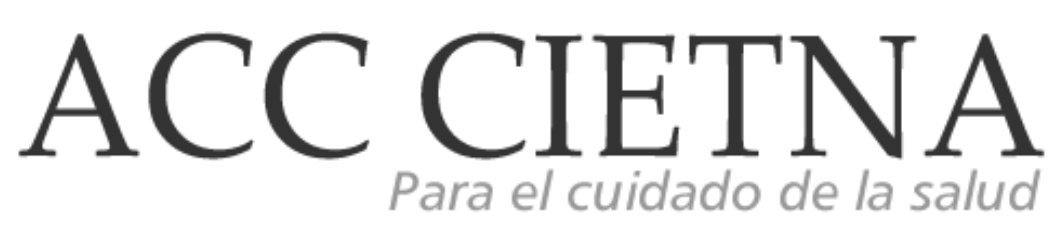

https://doi.org/10.35383/cietna.v1i2.158

\title{
Os modelos teóricos nos serviços de enfermagem na visão dos enfermeiros da assistência: um estudo exploratório
}

\author{
Pedrosa da Carpinteira Simone Fontes ${ }^{1}$, Ortiz Sanchez Maritza Consuelo ${ }^{2}$, Pereira Marilia de \\ Jesus $^{3}$, Ribeiro de Castro Magda ${ }^{4}$
}

\begin{tabular}{l} 
INFORMACIÓN DEL ARTÍCULO \\
\hline Historia del artículo: \\
Recibido el 23 de mayo de 2016 \\
Aceptado el 15 de junio de 2016 \\
\hline
\end{tabular}

\section{Palabras claves:}

Modelos teóricos

Sistematização da assistência de enfermagem

Enfermagem

\section{RESUMO}

Esta pesquisa tem como objeto de estudo a implementação dos modelos teóricos na Sistematização da Assistência de Enfermagem (SAE) na visão dos enfermeiros assistenciais. Tem por objetivo analisar os desafios enfrentados pelos enfermeiros para a implementação dos modelos teóricos nos serviços de enfermagem. A abordagem metodológica é de natureza qualitativa, descritiva e exploratória. Os sujeitos do estudo foram constituídos por onze enfermeiros que atuam na assistência, em diversas instituições de saúde na cidade do Rio de Janeiro, Brasil. Os resultados revelaram que mesmo os profissionais tendo conhecimento sobre a importância da escolha dos modelos teóricos para a implantação da SAE, esse processo ainda se encontra deficitário em nosso país em virtude de diversos fatores de ordem pessoal, profissional e institucional. Observa-se a necessidade de haver maior interesse por parte do enfermeiro e das instituições de saúde no sentido de investir no aprimoramento e na capacitação de pessoal para a implementação efetiva da SAE, visando à melhoria da qualidade dos serviços oferecidos à população, maior reconhecimento e valorização do profissional de enfermagem.

\footnotetext{
${ }^{1}$ Aluna do $6^{\circ}$ período do Curso de Graduação em Enfermagem do Centro Universitário da Cidade. Rio de Janeiro, Brasil. Email: sfpedrosa@gmail.com

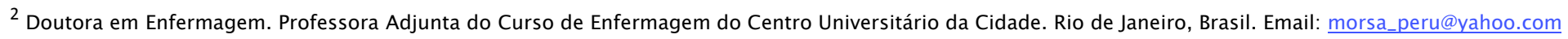

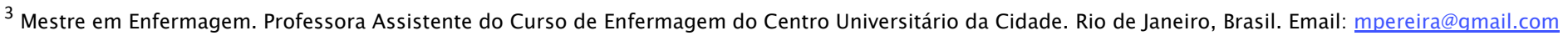

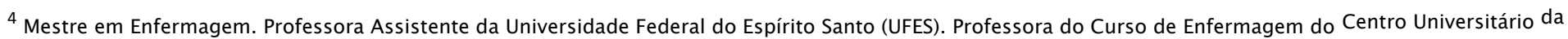
Cidade. Professora do Curso de Enfermagem da Universidade Estácio de Sá. Rio de Janeiro, Brasil. Email: mribeiro@gmail.com
} 
The theoretical models in nursing services in vision of nurses of assistance: an exploratory study

\section{ABSTRACT}

\section{Keywords:}

Theoretical models

Sistematization of nursing care Nursing
This research aims to study the implementation of theoretical models in the Nursing Care System (NCS) in the viewpoint of nurses. It aims to analyze the challenges faced by nurses to implement the theoretical models in nursing services. The methodological approach is qualitative, descriptive and exploratory. The study subjects consisted of 11 nurses working in care, in several health institutions in the city of Rio de Janeiro, Brazil. The results revealed that even when professionals know about the importance of the choice of theoretical models for the implementation of the NCS, this process is still deficient in our country, due to various personal, professional and institutional factors. There is a need for greater interest on the part of nurses and health institutions, to invest in upgrading and training of personnel for the effective implementation of the NCS in order to improve the quality of services offered to the population and greater recognition and enhancement of the nursing professional.

\section{Introdução}

Esta pesquisa tem por objeto de estudo a implementação dos modelos teóricos na Sistematização da Assistência de Enfermagem (SAE) na visão dos enfermeiros assistenciais.

Para sistematizar a assistência de enfermagem, é necessário haver um marco conceitual, ou seja, uma linha de pensamento que fundamente e determine a prática de enfermagem. Entre as linhas de pensamento que podem ser utilizadas, os modelos teóricos ou teorias de enfermagem revelam-se como as mais adequadas por serem escritas a partir de vivências da prática profissional, descrevendo as ações a serem realizadas pelos enfermeiros. ${ }^{1}$

A teoria de enfermagem pode ser conceituada como um conjunto de conceitos interrelacionados, definições e proposições capazes de direcionar uma forma de ver os fatos e os eventos. 2 Ou seja, as teorias são compostas de conceitos que visam descrever fenômenos, correlacionar fatores, explicar situações, prever acontecimentos e controlar os resultados obtidos a partir das ações de enfermagem executadas. ${ }^{1}$

Neste contexto, a motivação do estudo surgiu em decorrência de diversas leituras feitas em relação ao tema, onde se percebeu que apesar da importância da implementação da SAE nos serviços de saúde para a melhoria a qualidade da assistência, considerando-se que os modelos teóricos servem como guia para a sua implantação, observa-se, enquanto profissionais da área da saúde, as dificuldades dos enfermeiros no que diz respeito à colocação destes modelos em sua prática.

É importante ressaltar que o uso das teorias de enfermagem oferece estrutura e organização ao conhecimento de enfermagem, proporciona um meio sistemático de coletar dados para se descrever, explicar e prever a prática, promove a prática racional e sistemática, torna-a direcionada por metas e resultados e determina a finalidade da 
enfermagem, estabelecendo seus limites e promove um cuidado coordenado e menos fragmentado ${ }^{2}$.

Portanto, para que o enfermeiro possa escolher uma teoria de enfermagem para sistematizar a assistência do cotidiano de sua prática, faz-se necessário que ele tenha conhecimento da realidade do setor em que trabalha, do perfil dos enfermeiros que atuam nesta unidade, bem como a clientela atendida, uma vez que a caracterização desses elementos deverá estar em acordo com os conceitos da teoria selecionada. ${ }^{1}$

Para compreender melhor a Sistematização da Assistência de Enfermagem, deve-se reportar à Resolução do COFEN n $358 / 2009$, que refere que a SAE é uma atividade regulamentada pela a Lei $n^{\circ}$ 7.498 , de 25 de junho de 1986, e pelo Decreto $n^{\circ}$ 94.406, de 08 de junho de 1987, cuja função é organizar o trabalho profissional quanto ao método, pessoal e instrumentos, tornando possível a operacionalização do Processo de Enfermagem ${ }^{3}$.

O Processo de Enfermagem é um instrumento metodológico que orienta o cuidado de enfermagem e a documentação da prática profissional. Ou seja, é um modo organizado de prestar o cuidado ao cliente, sendo o instrumento e a metodologia da prática de enfermagem, ajudando ao enfermeiro tomar decisões, prever e avaliar as consequências 1 .

Cabe ressaltar que o Processo de Enfermagem deve estar baseado num suporte teórico que oriente a coleta de dados, o estabelecimento de diagnósticos de enfermagem, o planejamento, a implementação das ações ou intervenções de enfermagem e a avaliação dos resultados alcançados ${ }^{3}$.

O artigo $4^{\circ}$ da Resolução supracitada refere que é de responsabilidade do enfermeiro a liderança na execução e avaliação do Processo de Enfermagem,
cabendo-Ihe, privativamente, o diagnóstico de enfermagem acerca das respostas de pessoa, familia ou coletividade em um dado momento do processo saúde e doença, assim como a prescrição das ações ou intervenções de enfermagem a serem realizadas, de acordo com essas respostas ${ }^{3}$.

Ainda de acordo com a Resolução, o Processo de Enfermagem deve ser realizado de forma deliberada e sistemática, em todos os ambientes, públicos ou privados, em que ocorre o cuidado profissional de Enfermagem, considerando que a sua operacionalização e documentação evidencia a contribuição da Enfermagem na atenção à saúde da população, aumentando a visibilidade e o reconhecimento profissional. 3

Assim, os modelos teóricos funcionam como um alicerce estrutural para a implantação da Sistematização da Assistência de Enfermagem que, por sua vez, requer uma metodologia para ser implementada. O método utilizado para se implantar a SAE é o Processo de Enfermagem?.

No cenário nacional vivencia-se uma mudança paradigmática do modo de produzir saúde, que foi iniciada com o movimento da reforma sanitária na década de 1970 e que culminou com a criação do Sistema Único de Saúde (SUS). Neste contexto, diversos autores ressaltam que a Sistematização da Assistência de Enfermagem tem demonstrado potencialidades e dificuldades nos serviços de saúde, uma vez que sua implementação faz parte da reorganização e sistematização das práticas em saúde.

Nos dias de hoje, o enfermeiro se depara com mudanças tecnológicas, mercadológicas e processos complexos, devendo utilizar habilidade de reflexão crítica para a tomada de decisões, sendo ele o líder da equipe, responsável por organizar e sistematizar a assistência. A adequação a estas mudanças depende dos esforços dos atores envolvidos nos diversos cenários dos serviços, academia e comunidade, para que essa construção ocorra ${ }^{4-5}$. 
Entende-se que a SAE é uma ferramenta que favorece a melhoria da prática assistencial com base no conhecimento, no pensamento e na tomada de decisão clínica com o suporte de evidencias cientificas, obtidas a partir da avaliação dos dados subjetivos e objetivos do indivíduo, da família e da comunidade 1 .

Sendo assim, os enfermeiros precisam, cada vez mais, de conhecimentos acerca das Teorias de Enfermagem, do Processo de Enfermagem, da semiologia, da fisiologia, da patologia, além das habilidades necessárias para gerenciarem as unidades efetivamente. Dessa forma, será possível ao enfermeiro prestar assistência diretamente ao paciente/a família/a comunidade, de acordo com os indicadores de saúde obtidos através dos registros realizados nos prontuários pela equipe de enfermagem, podendo, então, avaliar a qualidade da assistência prestada e mensurar o quanto os profissionais contribuíram para a melhora do quadro dos pacientes sob seus cuidados ${ }^{1}$.

O enfermeiro, para prestar assistência de forma inovadora, isto é, com criatividade, autonomia e qualidade, necessita de conhecimento técnico científico. Desta forma, a implantação da SAE a partir de um conhecimento específico e da problematização acerca da organização, da filosofia, do produto e dos serviços de enfermagem, constituise um instrumento de fundamental importancia para que o profissional possa gerenciar e aperfeiçoar a sua assistência de forma organizada, dinâmica, competente e, de forma racional e universal, determinar sua área especifica de atuação6.

Este estudo se justifica por identificar, enquanto profissionais da área da saúde, os desafíos encontrados na implementação dos modelos teóricos na Sistematização da Assistência de Enfermagem, como uma ferramenta útil não só para a melhoria da qualidade do atendimento, mas também para a valorização do profissional da assistência, além de contribuir como futura fonte de pesquisa, preenchendo as lacunas ainda existentes nesta área.

Frente ao acima exposto foi elaborado o seguinte objetivo: analisar os desafios enfrentados pelos enfermeiros para a implementação dos modelos teóricos nos serviços de Enfermagem.

\section{Método}

A metodologia desta pesquisa é de abordagem qualitativa, descritiva e exploratória, ou seja, baseiase na descrição das experiências humanas, que corresponde a um espaço profundo das relações, dos processos e dos fenômenos que não podem ser reduzidos a operacionalizações de variáveis?.

Os sujeitos do estudo foram onze enfermeiros que trabalham em diversas instituições de saúde na cidade do Rio de Janeiro - Brasil.

Para a coleta de dados, utilizou-se um roteiro de entrevista semiestruturada, que é um instrumento que tem como característica a combinação de perguntas abertas e fechadas, onde o informante tem a possibilidade de discorrer sobre o tema proposto a partir de questões previamente definidas. 8 Tais questionamentos nos permitiram entender e analisar, a partir das respostas dos informantes, a importancia dos modelos teóricos e os desafios que os profissionais de enfermagem encontram na implementação dos modelos teóricos para que sua prática possa ter sustentação teórica nas diversas instituições de saúde.

A pesquisa foi realizada no período de julho de 2011. O projeto foi apreciado e aprovado pelo Comitê de Ética em Pesquisa do Curso de Enfermagem do Centro Universitário da Cidade e os sujeitos Esclarecido, que assegura os direitos dos mesmos ao assinaram o Termo de Consentimento Livre e participarem da pesquisa ${ }^{9}$. 
Para a análise do presente estudo seguiram-se três etapas: na primeira foi realizada a pré-análise, que consiste na organização, leitura e re-leitura do material, buscando coerência com os objetivos da pesquisa; na segunda etapa foi explorado o material, fazendo recortes do texto em unidades de registro, realizando essencialmente a operação de codificação, uma frase, uma palavra ou um tema; no terceiro e último passo os dados foram interpretados, colocando em evidencia as informações obtidas e fazendo inferências à luz da literatura existente 7,10 .

\section{Resultado, Análise e discussão}

Os achados mostram a importancia dos modelos teoricos nos serviços/prática de enfermagem, visto que possibilita a melhoria da qualidade da assitência e serve como norteador da prática profissional e mostra ainda alguns desafios enfrentados pelo enfermeiro no processo de implementação dos modelos teóricos tais como: fatores de órdem pessoal, fatores de órdem profissional e fatores de órdem institucional.

\section{Importância dos modelos teóricos nos serviços/práticas de enfermagem.}

Antes do desenvolvimento das teorias, a enfermagem possuía uma relação de subordinação frente à medicina. A prática de enfermagem dependia de outros e se destacava pela mera realização de tarefas, de caráter repetitivo, havendo pouca preocupação com a justificativa de suas ações².

É importante salientar que, historicamente, foi a partir do surgimento de Florence Nightingale que nasceu a preocupação da enfermagem com as questões teóricas. Afirmando que "o conhecimento e as ações de Enfermagem são diferentes das ações e conhecimento médico, uma vez que o interesse da enfermagem está centrado no ser humano e não na doença e na saúde propriamente ditas", no libro "Notas sobre Enfermagem: o que é e o que não é", publicado em 1859, Florence propôs premissas básicas para a prática de enfermagem. Em sua visão, os enfermeiros deveriam observar com precisão os doentes, suas condições de vida e a influência do ambiente de forma positiva ou não sobre a sua saúde ${ }^{1-2,11}$.

Apesar de Florence não apresentar seu trabalho como uma "teoria de enfermagem", também classificada por alguns estudiosos como uma ampla filosofia, ele orientou a prática da enfermagem por mais de 100 anos 2,12 .

A filosofia para a prática de enfermagem proposta por Florence ficou conhecida como Teoria Ambientalista, e os princípios que deveriam servir de fundamento para os cuidados de enfermagem se relacionam aos seguintes fenômenos: ventilação (ou ar fresco), iluminação, aquecimento, quietude (ou silêncio), limpeza, pontualidade e cuidado na administração da alimentação ${ }^{13}$.

Sob o ponto de vista de Florence, a enfermagem é tida não como uma prática de cura, mas como uma prática que tem como principal função colocar o paciente em suas melhores condições para que a natureza possa agir sobre ele. O papel da enfermeira seria então o de ajudar o doente a manter suas forças vitais a fim de prevenir a doença, resistir a ela ou recuperarse ${ }^{13}$.

Apesar de Florence idealizar uma profissão com embasamento científico, a enfermagem assumiu uma orientação profissional dirigida para o imediatismo, utilizando ações práticas de modo intuitivo e não sistematizado. Os enfermeiros passaram a exercer a profissão tendo como base o modelo biomédico, centralizando suas ações na doença e não propriamente no cliente. Por este motivo, a prática de enfermagem acostumou-se a depender de conhecimentos pré-existentes capazes de lhe definir "o que fazer" e "como fazer", na maioria das vezes não refletindo no "por que" fazer e "quando" faze'. 
Com o passar do tempo, em decorrência das transformações sociais, econômicas e políticas, do desenvolvimento da ciência no mundo e da percepção da necessidade de condições menos servis para a profissão, surgiu a consciência da necessidade das enfermeiras serem mais preparadas, através do aprimoramento educacional, a fim de alcançarem a melhoria da qualidade do cuidado prestado à população. Para isso, era preciso desenvolver um corpo específico e organizado de conhecimentos sobre a profissão, permitindo que o significado da enfermagem e seu papel social fossem difundidos'.

Nos dias atuais, observa-se a influência das Teorias e dos Modelos de Assistência de Enfermagem no contexto da enfermagem brasileira, uma vez que estão cada vez mais difundidos, seja na prática da enfermagem quanto na formação de profissionais enfermeiros. Estes modelos são representações do mundo vivido, expressos verbalmente ou por meio de símbolos, esquemas, desenhos, gráficos, diagramas, tendo como objetivo direcionar a assistência de enfermagem, oferecendo ao enfermeiro subsidios necessários para sua atuação ${ }^{14}$.

\section{Melhoria da qualidade da assistência}

A melhoria da qualidade na assistência de enfermagem tem configurado uma necessidade de revisar e modificar a prática e o papel do profissional de enfermagem, no sentido de imprimir uma nova característica à sua atuação, garantindo reconhecimento profissional ${ }^{15}$.

Diante do exposto, pode-se observar que grande parte dos enfermeiros entrevistados demonstrou em suas respostas ter conhecimento da importância da utilização dos modelos teóricos para haver uma assistência de qualidade, como nos mostram as falas a seguir:

[...] a gente ganha em tempo e ganha em qualidade. (Depoimento 1)
[...] o comprometimento da qualidade. (Depoimento 6)

\section{[...] no favorecimento da excelência em qualidade} assistencial. (Depoimento 10)

Um modelo de assistência embasado cientificamente conduz-nos ao fazer reflexivo, a estar sempre buscando a melhoria da assistência prestada. Levanos a refletir que os modelos nos auxiliam na percepção de que praticar enfermagem não se trata de uma ordenação de procedimentos mais ou menos constantes, de acordo com a situação, ela é um processo dinâmico, mutável e criativo, não deixando de ser um processo conhecível, objetivo, programável e decifrável.

Portanto, quanto mais claro for o referencial teórico do modelo aplicado, maior será a segurança e a realização profissional do enfermeiro, maior será o direcionamento da equipe de enfermagem, culminando com uma assistência adequada às necessidades apresentadas pelo indivíduo assistido ${ }^{14}$.

Outro ponto observado em relação à importância da utilização das teorias foi o fato dos depoentes identificarem a implementação dos modelos teóricos como sendo parte da Sistematização da Assistência de Enfermagem. As falas a seguir nos elucidam esta questão:

\section{[...] A sistematização da enfermagem é} fundamental para um serviço de referência, pois proporciona uma assistência planejada $e$ organizada, refletindo na melhora da saúde de seus clientes, tais como:diagnóstico de enfermagem,com fase intermediária para o alcance, a informática; prescrição de enfermagem; evolução de enfermagem; anamnese, que resume no histórico do paciente com exame físico; identificação da problemática do cliente.[...]. (Depoimento 7)

[...] Na minha opinião os modelos teóricos são de suma importância para a implementação, o 
desenvolvimento e a prática da minha assistência quanto enfermeira em uma unidade hospitalar. Através dele obtenho todo o conhecimento do cliente em seu histórico, dinamizo seu tratamento, facilito o meu trabalho e o da equipe de enfermagem, fornecendo a eles dados suficientes para a promoção, prevenção e causando assim uma aceleração na sua recuperação e reabilitação [...]. (Depoimento 8)

\section{[...] Quando o enfermeiro se apropria dos modelos} teóricos no decorrer de sua prática asistencial permite uma aproximação com seu contexto, sua relação com a clientela e equipe. (Depoimento 10)

[...] A importância dos modelos teóricos está na implementação da Sistematização da Assistência de Enfermagem (SAE), uma vez que, o enfermeiro, no exercício do processo de enfermagem estabelece uma relação de aproximação com uma das teorias e com isso, interage com o cliente, sua equipe e familiar cuidador, oportunizando uma prática diferenciada frente à equipe de saúde [...]. (Depoimento 11)

É de responsabilidade da equipe, liderada e assistência prestada através da Sistematização da Assistência de Enfermagem (SAE), que é um dos meios que o enfermeiro dispõe para aplicar seus conhecimentos técnico-científicos e humanos na assistência ao paciente e caracterizar a sua prática profissional, colaborando na definição do seu papel. A SAE oferece respaldo cientifico, segurança e direcionamento para as atividades realizadas, coordenada pelo enfermeiro, a qualidade da gerando maior credibilidade, competência e visibilidade da enfermagem, maior autonomia e satisfação profissional1. Para isso, é necessário que o processo seja guiado por uma teoria de enfermagem, capaz de fundamentar a organização do serviço e tornar operacionalizáveis os resultados da assistência prestada aos pacientes.

Além disso, foram encontradas similaridades entre diversas pesquisas realizadas sobre o assunto e as mesmas referem que o Processo de Enfermagem realmente possibilita maior interação com o paciente, família, comunidade e com a própria equipe multidisciplinar².

Um dos depoentes referiu que a Sistematização da Assistência de Enfermagem traz como vantagem a otimização do tempo, além de facilitar a provisão de recursos materiais de acordo com as necessidades da clientela, como se pode ver a seguir:

\section{[...] em $l^{\circ}$ lugar a otimização do tempo [...] com} essa otimização a gente não fica reproduzindo o trabalho

[...] a gente ganha em tempo e ganha em qualidade [...] quem ganha [...] com isso é o nosso cliente [...]. Eu acho importante [...] saber o que eu tenho dentro de recursos de materiais [...] também saber o que esta acontecendo com cada cliente que esta entrando na minha enfermaria [...] e o [que] ele vai precisar.

Isso é importante porque me agiliza na hora que eu precisar [...] prestar um cuidado mais rápido. [...] Acho que [...] [o] enfermeiro tem essa capacidade de provisão de tudo. (Depoimento 1)

Muitas vantagens são obtidas por meio da Sistematização da Assistência, como otimização do tempo, direcionamento das ações de enfermagem, maior facilidade na passagem de plantão e principalmente, para o paciente, por tornar $o$ atendimento de enfermagem personalizado, eficiente e eficaz ${ }^{3}$.

É importante ressaltar que nas funções relativas à administração de recursos materiais, o enfermeiro é responsável pela previsão, provisão organização e controle dos materiais. Assim, ele deve estar atento à qualidade do material utilizado e à quantidade satisfatória, com o objetivo de melhorar a assistência ao paciente, minimizando os riscos e garantindo a continuidade do atendimento, além de proporcionar melhores condições de trabalho ao pessoal de enfermagem 
e demais membros da equipe de saúde. E isso só será possível sistematizando a assistência ${ }^{16}$.

\section{Norteador da prática assistencial.}

Os modelos teóricos de enfermagem foram elaborados para retratar conceitos, descrever, explicar, prever fenômenos e determinar o campo de domínio da profissão. Desde o início, havia uma busca por respostas para questões acerca de quem é o enfermeiro, quem é o indivíduo que recebe o cuidado, quais conceitos deveriam orientar o modelo da assistência de enfermagem e como se poderia tornálo conhecido para os profissionais, de modo que eles pudessem guiar a prática clínica mantendo a consonância com as políticas das instituições de saúde ${ }^{1}$.

Assim, as teorias de enfermagem são fundamentadas em conceitos inter-relacionados e devem ser encaradas no contexto da maneira pela qual elas descrevem sua abordagem para a prática, ou seja, através dos conceitos que representam a ideologia da enfermagem: pessoa, ambiente, saúde e enfermagem.

Estes conceitos também são conhecidos como metaparadigmas da enfermagem².

Como para escolher a teoria que melhor fundamente o processo de cuidar é preciso que haja congruencia entre os conceitos estabelecidos pelos modelos teóricos e o cotidiano de trabalho do enfermeiro, torna-se evidente que estes modelos direcionam as ações dos enfermeiros, de modo a torná-los responsáveis pela assistência a ser prestada'.

Com base neste argumento, ficou notória a relevancia dos modelos teóricos como um norteador da prática assistencial pelos enfermeiros entrevistados:

[...] é importante, com certeza daria um norte, um norteador pra essa assistência. (Depoimento 1)
Os modelos teóricos, eles servem como respaldo e embasamento científico para assistência de enfermagem. De acordo com o tipo de assistência, de acordo com a abordagem que a gente dá no serviço, [...] nós podemos [...] selecionar as teorias, a teoría que mais se adapta ao nosso trabalho, à nossa filosofia de trabalho, e depois embasar o estudo. (Depoimento 2)

[...] é um grande norteador, é como a gente aquí trabalha com ambulatório, esse ambulatório a gente pode implementar uma teoria de auto cuidado ele ajuda muito no nosso caminho. (Depoimento 4)

Ainda neste contexto, no depoimento a seguir observam-se alguns dos elementos fundamentais que representam o conteúdo nuclear das teorias de enfermagem:

Um modelo teórico serve para nortear, para direcionar a prática de enfermagem, para dar uma base, uma fundamentação no processo do nosso trabalho, [...] dependendo do modelo, você vai adotar uma conduta ou um caminho melhor no seu dia-a-dia, nas suas práticas, no seu planejamento, na sua assistência, [...] conhecendo todas as teorias a que mais se adequar [...] a sua clientela, a que mais se adequar à sua realidade, então você define um modelo que vai te direcionar, te encaminhar, te conduzir, todas as suas ações, planejamento, de sistematização, de prática, de todos os dias, na sua prática profissional. (Depoimento 3

Como mencionado anteriormente, para se compreender as teorias de enfermagem, é de suma importância entender os conceitos dos metaparadigmas da enfermagem: a pessoa; a saúde; o ambiente e a enfermagem. Os metaparadigmas da enfermagem esclarecem quem é aquele que recebe o cuidado de enfermagem (pessoa), qual a finalidade da assistência de enfermagem (saúde - um estado de bem estar decidido mutuamente pelo cliente e pelo enfermeiro), em qual ambiente essa assistência é 
prestada (que pode representar o entorno imediato em que se encontra a pessoa que recebe a assistência de enfermagem ou a comunidade, a moradia, o ambiente de trabalho ou o universo), e como essa assistência deve ser executada (papel do enfermeiro) ${ }^{1-2}$.

Através destes elementos, os modelos teóricos de enfermagem refletem o modo de visualizar a realidade, facilitando a compreensão, o raciocínio, ou seja, organizando o pensamento, a observação, a interpretação do que se vê e, consequentemente, a comunicação entre os profissionais ${ }^{1}$.

Ressalta-se que duas das depoentes fizeram referência à possibilidade de que as teorias permitem falar a mesma linguagem:

\section{[...] ajuda a equipe a falar a mesma linguagem. (Depoimento 9)}

\section{[...] adequação da linguagem no decorrer da} implementação da prática assistencial. (Depoente 11)

Para falarmos a mesma linguagem se faz necessária a padronização das atividades, que têm como objetivo criar uma identidade, individualizar o serviço de enfermagem, com a aplicação de processos científicos à pratica do serviço, além de sistematizar a execução das atividades por parte dos diversos profissionais'.

\section{Desafios enfrentados pelo enfermeiro no processo de implementação dos modelos teóricos.}

A implementação dos modelos teóricos representa o início de um processo lento, dinâmico e gradual, que pressupõe a superação de resistências, temores, crenças e barreiras associadas à política e filosofía institucional e de enfermagem. Assim, a metodologia de escolha para o desenvolvimento do processo é de fundamental importância, tendo em vista que a sua construção implica em uma mudança de paradigmas no modo de ser e compreender o papel do enfermeiro na prática assistencial6.
Assim, ao analisarmos os desafios enfrentados pelos enfermeiros na implementação dos modelos teóricos, foram identificadas questões de ordem pessoal, profissional e institucional como fatores relacionados, muitos deles associados diretamente à implementação da SAE.

Fatores de ordem Pessoal. Os fatores de orden pessoal levam em consideração o universo dos significados, dos motivos, das aspirações, das crenças, dos valores e das atitudes dos enfermeiros envolvidos no processo de implementação ${ }^{3}$, como mostram as falas a seguir.

\section{[...] eu percebo [...] uma resistência de alguns} profissionais [...] o enfermeiro não enxerga seu potencial [...] realmente o maior desafio é estar convencendo o enfermeiro do potencial que eletem, e não que seja mais uma carga pra cima dele. (Depoimento 1)

\section{[...] própria vontade do profissional de} implementar todas as etapas do processo, baseado em uma teoria [...] (Depoimento 2)

\section{[...] interesse pessoal. (Depoimento 3)}

\section{[...] por falta de interesse. (Depoimento 11)}

Todo indivíduo traz consigo seus valores, suas crenças, suas motivações, pontos de vista que muitas das vezes podem estar dificultando que o enfermeiro cumpra seu papel social. A compreensão desses aspectos é fundamental para o reconhecimento do conceito e do significado de cuidar para o profissional de saúde, pois a tarefa de cuidar é um dever humano. Cuidamos porque queremos ser mais felizes, plenos, e para alcançarmos a felicidade é fundamental que cuidemos bem de nós mesmos e dos outros. A condição humana é tão frágil quanto efêmera, requer equilíbrio e constantes cuidados pessoais, sociais e ambientais ${ }^{17-18}$. 
Fatores de ordem Profissional. Os profissionais, em sua maioria, fizeram referência à falta de conhecimento como um dos desafios a enfrentar na implementação dos modelos teóricos nos serviços de enfermagem, nos seguintes termos:

[...] falta de conhecimento do profissional sobre a importância das teorias de enfermagem, bem como a implantação do SAE dentro das unidades. (Depoimento 2)

[...] não consegue reconhecer que esta fazendo uma sistematização da assistência de enfermagem e por falta de conhecimento da sistematização $e$ das teorias, então acaba [...] não conseguindo, [...] na prática [...] fundamentar o que esta sendo aplicado, o trabalho real. (Depoimento 3)

[...] Falta conhecimento metodológico de assistência, deficiência na abordagem da temática e grande demanda de serviços burocráticos $e$ administrativos. (Depoimento 6)

Quanto aos desafios enfrentados por nós enfermeiros diante da implementação desses modelos [...] ter o total conhecimento da SAE para saber aplicar, treinar, capacitar e incentivar a equipe de enfermagem, de modo que o cliente seja beneficiado com sua recuperação [...] com alta hospitalar o quanto antes previsto. (Depoimento 8)

[...] Conscientizar a equipe da importância do conhecimento técnico e da sua área de atuação.

(Depoimento 9)

\section{[...] Conhecimento científico baseado em evidências. (Depoimento 10)}

[...] é a falta de aprofundamento teórico-cientifico. (Depoimento 11 )

A falta de conhecimento sobre o Processo de Enfermagem é o motivo fundamentador da execução descompromissada deste método assistencial em algumas instituições de saúde e da sua não-implementação em outras. $\mathrm{O}$ desconhecimento gera desinteresse e a não adesão da metodologia, comprometendo assim a Sistematização da Assistência de Enfermagem ${ }^{15}$.

Estudos apontam que para a efetiva implantação dos modelos teóricos na SAE e para a continuidade da metodologia com sucesso é necessário que o enfermeiro esteja preparado com conhecimentos científicos, além de estar em constante atualização ${ }^{19-20 .}$

O enfermeiro deve assumir uma prática comprometida com a SAE, sendo capaz de refletir e reconhecer as barreiras históricas e culturais da sua formação, baseadas mais especificamente no modelo técnico-burocrático e, dessa maneira, desencadear um processo de mudança em seu papel6.

No que diz respeito à atualização, transcrevo a fala de um dos depoentes que elucida este tópico da seguinte maneira:

[...] a enfermagem também precisa de uma capacitação diária e contínua para poder estar dando continuidade a essa implementação. (Depoimento 5)

Torna-se impossível a implantação efetiva da SAE ocorrer sem que a equipe de enfermagem esteja devidamente preparada, sob o ponto de vista do conhecimento científico (fundamentação teórica) e da habilidade prática. Portanto, deve fazer parte das etapas de planejamento para a sua implantação, o reconhecimento da necessidade de capacitação da equipe de enfermagem e do investimento, se necessário, no preparo para o desempenho dessa prática ${ }^{21}$.

No que diz respeito à implementação da SAE propriamente dita, deve-se atentar para o seguinte discurso:

[...] a regulamentação, as novas leis, as diretrizes apontando para a importância da sistematização contribui também pra facilitar e dar mais peso para 
o quanto é importante a enfermagem sistematizar a assistência [...] fundamentada no modelo teórico. (Depoimento 3)

A SAE tem sido alvo de discussões desde o início da década de 70, (na época conhecida simplesmente por Processo de Enfermagem) visando à eficácia da assistência e ampliando a definição do espaço da enfermagem na equipe de saúde.

Neste contexto, cabe ressaltar o trabalho de Wanda de Aguiar Horta, primeira enfermeira brasileira a falar de teoria no campo profissional na segunda metade dos anos 1970. Horta teve como base a Teoria da Motivação Humana de Abraham Maslow para elaborar a Teoria das Necessidades Humanas Básicas, trazendo um grande avanço ao desenvolvimento da enfermagem brasileira introduzindo a proposta de uma assistência de enfermagem sistematizada, realizada então através do Processo de Enfermagem ${ }^{1}$.

Deve-se destacar que a enfermagem brasileira através da Resolução COFEN 358/2009, que dispõe sobre a Sistematização da Assistência de Enfermagem e a implementação do Processo de Enfermagem em ambientes, públicos ou privados, em que ocorre o cuidado profissional de Enfermagem, tornou obrigatória a implementação da SAE nas instituições de saúde públicas e privadas $^{3}$.

Como dito inicialmente, a Sistematização da Assistência de Enfermagem (SAE) é uma atividade privativa do enfermeiro, regulamentada pela a Lei $\mathrm{n}^{\circ} 7.498 / 1986$ e pelo Decreto $\mathrm{n}^{\circ}$ 94.406/1987, considerando a evolução dos conceitos de Consulta de Enfermagem e de Sistematização da Assistência de Enfermagem, sendo sua implantação imprescindível para diferenciação e valorização dos profissionais de enfermagem. Essa sistematização proporciona assistência individualizada e de excelência para o cliente ${ }^{3-4}$.
Outra das questões destacadas por um dos depoentes, no que diz respeito aos desafios na implementação dos modelos teóricos, é a dicotomia entre a teoria e a prática, como pode ser observado a seguir:

[...] distanciamento ainda muito grande da teoría prática [...] O que eu vivencio é que a teoria ela fica na academia, então o aluno, o enfermeiro, depois quando ele se forma nem sempre consegue levar, e fazer a ponte, fazer a interseção [...] aplicabilidade dessa teoria no dia a dia dele na prática, então fica uma coisa dicotomizada. (Depoimento 5)

\section{[...] outro é difundir melhor, fazer com que o enfermeiro na graduação aprenda melhor essas teorias, coloque melhor em prática, consiga aplicar melhor essa teoria no trabalho dele, na sistematização da assistência de enfermagem. (Depoimento 3)}

A falta de integração entre a teoria e a prática sobre o cuidado integral e holístico depara-se com uma enorme distância entre o vivenciado na escola e a precariedade das condições de trabalho com que os profissionais se deparam, após a sua formação, nas instituições de trabalho, o que, de certo modo, dificulta a aplicação prática do que foi aprendido durante a graduação 22 .

Assim, a não utilização do processo de enfermagem pelos profissionais deve-se ao distanciamento muito grande entre o pensar e o fazer, entre a teoria e a prática. Portanto, a experiência no ensino de enfermagem tem mostrado que os ideais profissionais de autonomia, poder e prática reflexiva parecem ser realidades diferentes na sala de aula e na prática clínica ${ }^{23}$.

Questões relativas à falta de comunicação também foram evidenciadas na fala de um depoente como um desafio a ser superado:

[...] O maior desafio do enfermeiro [...] é a falta de 
comunicação entre a equipe de enfermagem e a equipe multidisciplinar da área de saúde, organização no atendimento qualificado de um dificultando a possibilidade de uma melhor profissional que visa um atendimento humanitário [...]. (Depoimento 7

O processo de comunicação interfere diretamente na recuperação do paciente, pois o serviço assistencial de saúde intenciona, através de atributos de eficiencia e efetividade técnica, proporcionar um entendimento harmonioso entre ele, a equipe de enfermagem e os demais profissionais e, consequentemente, um melhor atendimento. Nesse sentido, o preparo da equipe de saúde para uma relação de comunicação é imprescindível para o bom resultado de suas ações assistenciais ${ }^{24}$.

Apesar da Lei do Exercício Profissional de Enfermagem (Lei $n^{\circ} 7.498 / 1986$ ) e de seu decreto regulamentador (Decreto $n^{\circ}$ 94.406/1987) estabelecerem a Consulta de Enfermagem (também denominada Sistematização da Assistência de Enfermagem) como atividade privativa do Enfermeiro, e da Resolução COFEN159/1993 garantir o direito à sua implementação em todos os níveis de assistência à saúde, ainda hoje, por falta de conhecimento dos próprios profissionais, o enfermeiro deixa de realizar as tarefas que são de sua competência e que estão amparadas por lei, contribuindo para o não reconhecimento de suas funções pela sociedade, conforme nos elucida a fala a seguir 3,25 .

\section{[...] a falta de reconhecimento do exercício} profissional de enfermagem frente à sociedade. Os próprios enfermeiros não exercem suas atribuições respaldadas por lei, por não possuírem conhecimento. (Depoimento 11)

\section{[...] falta de reconhecimento também do trabalho [...] e da instituição.(Depoimento 3)}

A busca da valorização da profissão nas instituições de saúde sempre foi uma luta constante dos profissionais de enfermagem, seja para ocupar cargos que representem status administrativos e prestígio dentro das instituições para tomada de decisões, assim como para reivindicações por um atendimento de qualidade à clientela, melhores condições de vida e de salário26.

A valorização da enfermagem enquanto profissão depende da postura do profissional frente aos problemas que emergem da sua prática. $O$ enfermeiro precisa ser autêntico e conquistar o seu espaço com mérito, através do uso do seu conhecimento científico especifico, que lhe dará a autonomia necessária para desenvolver um trabalho consciente, eficiente e gratificante, do ponto de vista de resultados positivos na assistência prestada ${ }^{19}$.

Acredita-se que a autonomia na profissão só será alcançada quando toda a classe começar a utilizar essa metodologia científica, ou seja, quando estiver em prática a aplicação sistemática do Processo de Enfermagem, que se operacionaliza em cinco etapas, a coleta de dados, o diagnóstico de enfermagem, o planejamento de enfermagem, a implementação da assistência e a avaliação de enfermagem ${ }^{1,3}$.

Fatores de ordem Institucional. As transformações apontam para um redirecionamento dos objetivos da organização institucional; antes voltadas para o controle da produção de bens e serviços, agora passam a se basear na informação, na tecnologia e no consumo. Em consequência, a gerência praticada nas instituições se volta para a valorização da descentralização administrativa, da comunicação informal, da flexibilidade nos processos de produção, assim como para o estimulo à iniciativa e à criatividade dos indivíduos e do grupo 27.

Nesta subcategoria, segundo alguns depoentes, entre os muitos fatores que prejudicam a implementação da SAE no âmbito da organização, destacam-se a carencia de pessoal de enfermagem 
e de recursos materiais, problemas estruturais e organizacionais e questões ligadas ao relacionamento multiprofissional, como se pode ver de acordo com as falas a seguir:

[...] a gente trabalha em uma unidade de pronto atendimento, onde tem 1 enfermeiro no serviço todo atendendo uma média de 200 pacientes dia; com certeza ele não vai ter uma boa institucionalização. (Depoimento 5)

[...] número reduzido de enfermeiros; nós podemos ter... Temos um setor que tem 1 enfermeiro só para atender 60 leitos, ou então esse enfermeiro é diarista, só vai de 7 às $13 \mathrm{~h}$ da tarde pra fazer pedido de material [...]. (Depoimento 2)

[...] além de falta de pessoal e de materiais, em sua maioria problemas conceituais, estruturais $e$ organizacionais. (Depoimento 6)

\section{[...] recursos humanos e materiais. (Depoimento 10)}

Os recursos humanos são um dos fatores mais relevantes na operacionalização da SAE, tanto no aspecto quanti-qualitativo, quanto no que se refere à função de cada elemento da equipe. No aspecto organizacional, a falta de pessoal de enfermagem/enfermeiros é o fator que predomina, prejudicando a implementação da SAE. Uma vez que essa prática exige a presença ininterrupta dos enfermeiros nas unidades, esta é uma variável que precisa ser considerada no dimensionamento e seleção de pessoal. Essas afirmações permitem questionar se as instituições de saúde brasileiras estão preparadas e interessadas em aumentar seu quadro de enfermeiros, em quantidade suficiente que garanta a implantação efetiva dessa metodologia21.

Os diretores de hospitais costumam não privilegiar espaços para a correta estocagem de materiais e medicamentos. Alguns poucos confundem almoxarifado com depósito, sem nenhum controle. $\mathrm{O}$ mesmo se pode comentar em relação à atenção aos recursos humanos que atuam na área. Nem sempre os funcionários são devidamente valorizados ou recebem o treinamento adequado $^{28}$.

Com relação aos problemas estruturais e organizacionais, inclusive associadas às relações de poder entre os profissionais podem ser observadas de acordo com as falas a seguir:

\section{[...] problema [...] administrativo do próprio hospital. (Depoimento 2)}

[...] as barreiras impostas pelo sistema de saúde como redação em prontuários restrita aos médicos; ausência de discussão de casos clínicos pelos enfermeiros do plantão; falta de impressos adequados para estimulação da implementação da assistência. (Depoimento 11)

As fases do planejamento para a implementação da SAE revelam um processo bastante complexo, e que, antes de tudo, faz-se necessário conhecer a estrutura institucional onde ela será implantada. Além disso, é preciso distinguir os aspectos que podem contribuir para a sua implantação e os que podem prejudicá-la21.

Médicos e profissionais de enfermagem, no desempenho de suas funções diferenciadas, nem sempre conseguem se comunicar adequadamente em função do saber que o médico detém para se apropriar do objeto do trabalho e conduzir a produção do assistir. Muitas vezes, o médico altera condutas e não comunica aos demais agentes, dificultando o trabalho cooperativo29.

Ao mesmo tempo, é importante lembrar que a enfermagem é uma profissão de mulheres e como tal, no processo histórico de sua evolução, sempre foi considerada como elemento de apoio, sempre subordinado, e nunca como agente principal das ações sociais. Em muitos lugares a assistência de enfermagem ainda é subsidiada pelo trabalho do médico e, quanto às Enfermeiras, estão habituadas 
a cumprir ordens, a esperar que lhes digam o que fazer e como devem se conduzir ${ }^{30}$.

Atualmente, na prática profissional, observa-se, muitas vezes, a ausência de um posicionamento questionador e de caráter científico por parte da enfermeira, ainda mantendo atitudes de obediência e submissão às ordens médicas e, consequentemente, enfrentando dificuldades e a falta de cooperação por parte dos membros da equipe multiprofissional ${ }^{30}$.

\section{[...] modelo arcaico [...] trabalhar com a equipe} médica, sentar e discutir, ver o melhor para o cliente, eu acredito na enfermagem assim, mesmo tendo sido formada naquele modelo clássico onde o enfermeiro era apenas um mero executor de tarefas. (Depoimento 1)

O cumprimento das tarefas com exatidão, firmeza e disciplina sempre foi exigido na enfermagem como mola mestra para a execução de uma assistência dita de qualidade, mesmo que isto implique em uma assistência que prioriza a execução de técnicas, sem levar em consideração a forma como o paciente sente, percebe ou recebe o cuidado 30 .

A utilização da SAE favorece o desenvolvimento dos papéis específicos da enfermagem e demonstra a complexidade do cuidado prestado. Além disso, contribui para que o profissional deixe de ser um mero executor de tarefas, e passe a ser membro real e integrante da equipe de saúde, capaz de avaliar suas ações, produzindo melhoria real na qualidade da assistência ${ }^{31}$.

O fato de o trabalho estar sendo influenciado pela divisão social reflete no atendimento fragmentado ao paciente, como nos mostra a fala a seguir:

\section{[...] por mais que a gente tenha avançado no tempo} você ainda vê que o nosso cliente é segmentado, uma parte é [...] de competência da nutrição, parte é [...] de competência do médico [...]. (Depoimento 1)
O processo de trabalho em saúde está baseado em regras de fragmentação, rotinização e centralização nas funções a serem executadas pelos diversos profissionais ${ }^{5}$.

Estudos mostram que a prática de enfermagem ainda está centrada no modelo médico hegemônico, o qual privilegia práticas prioritariamente curativas, fragmentadas e de baixa resolutividade. Apesar disso, instituídos em busca da promoção da saúde e da inúmeros esforços por parte dos enfermeiros têm sido integralidade da assistência32.

\section{Considerações Finais}

Através do presente estudo, pode-se perceber que os profissionais participantes da pesquisa possuem conhecimento sobre importância da escolha do modelo teórico na implementação da Sistematização da Assistência de Enfermagem, a fim de promover a melhoria da qualidade da assistência. Por se tratar de um norteador no qual o profissional terá condição de elaborar seu plano assistencial, visando cumprir as metas do serviço e da organização de enfermagem e com coerência à filosofia institucional, o reconhecimento do real papel do enfermeiro é fundamental para garantir a implementação dos modelos e da continuidade da SAE.

Foram também evidenciados fatores relacionados aos desafios enfrentados pelos enfermeiros no processo de implementação dos modelos teóricos, nos quais são encontrados fatores de ordem pessoal, tais como a falta de interesse por parte dos profissionais envolvidos, fatores de ordem profissional, como a falta de conhecimento técnico-científico, habilidade, preparo adequado na graduação, desconhecimento da legislação profissional, e os fatores de ordem institucional, que apontam a falta de apoio institucional, de reconhecimento profissional e a ausência de recursos. 
Diante dos fatos apresentados concluímos que ainda é deficitário o processo de implementação dos modelos teóricos e da própria Sistematização da Assistência em nosso país, observando a necessidade de haver maior interesse por parte das instituições de saúde no sentido de investir no desenvolvimento da educação continuada voltada para o aprimoramento e capacitação de pessoal, a fim de incentivar os enfermeiros e despertar o seu interesse em implementar uma assistência de forma organizada e mais eficaz, visando a melhoria da qualidade dos serviços oferecidos à população, de acordo com suas necessidades e, ao mesmo tempo, trazendo praticidade ao trabalho da equipe multidisciplinar, maior reconhecimento e valorização do profissional de enfermagem.

\section{Referências Bibliográficas}

1 Tannure MC, Pinheiro AM. SAE: Sistematização da Assistência de Enfermagem: guia prático. $2^{\mathrm{a}}$ ed. Rio de Janeiro: Guanabara Koogan; 2010.

2 McEwen, Melanie; Wills, Evelyn M. Bases Teóricas para Enfermagem. $2^{\text {a }}$ ed. Porto Alegre(RS): Artmed; 2009.

3 Conselho Federal de Enfermagem (Br). Resolução COFEN 358/2009. [acesso em 10 abr 2011]. Disponível

em:http//www.portalcofen.gov.br/node/4384

4 Felix NN, Rodrigues CDS, Oliveira VD. Desafios encontrados na realização da sistematização da assistência de enfermagem (SAE) em unidade de pronto atendimento. Arq Cienc Saúde 2009 out/dez; 16(4): 155-60.

5 Castilho NC, Ribeiro PC, Chirelli MQ. A implementação da sistematização da assistência de enfermagem no serviço de saúde hospitalar do Brasil. Texto Contexto Enferm [periódico na internet] $2009 \mathrm{abr} /$ jun [acesso em $04 \mathrm{abr} 2011$ ]; 18(2): 280-9.
Disponível em: http//www.scielo.br/ $\mathrm{pdf} / \mathrm{tce} / \mathrm{v} 18 \mathrm{n} 2 / 11$.pdf

6 Backes DS, Schwartz E. Implementação da sistematização de enfermagem: desafios e conquistas do ponto de vista gerencial. Ciência Cuidado Saúde [periódico na internet]. 2005 maio/ago [acesso em 04 abr 2011]; 4(2): 182-8. Disponível em:

http://periodicos.uem.br/ojs/index.php/CiencCui dSaude/article/viewFile/5247/3374

7 Minayo MCS. Pesquisa social: teoria, método e criatividade. $21^{\text {a }}$ ed. Petrópolis(RJ): Vozes; 2002.

8 Boni V, Quaresma SJ. Aprendendo a entrevistar: como fazer entrevistas em Ciências Sociais. Rev Eletrônica dos Pós-Graduandos em Sociologia Política da UFSC. [periódico na internet] 2005 jan/jul [acesso em 23 maio 2011]; 2(1): 68-80. Disponível em: www.emtese.ufsc.br

9 Ministério da Saúde (Br). Resolução 196/96 do Conselho Nacional de Saúde/MS sobre diretrizes e Normas Regulamentadoras de Pesquisa envolvendo seres humanos. Diário Oficial da União, Brasília (DF); 10 out 1996.

10 Minayo MCS. O desafio do conhecimento: pesquisa qualitativa em saúde. $11^{\text {a }}$ ed. São Paulo(SP): Hucitec-Abrasco; 2008.

11 Nightingale F. Notas sobre enfermagem: o que é e o que não é. São Paulo(SP): Cortez; 1989.

12 George JB. Teorias de Enfermagem: os fundamentos à prática profissional. $4^{\mathrm{a}}$ ed. Porto Alegre(RS): Artes Médicas Sul; 2000.

13 Leopardi MT, organizador. Teorias de Enfermagem: instrumentos para a prática. Florianópolis(SC): Papa-Livros; 1999.

14 Carraro TE, Westphalen MEA. Metodologias para a assistência de enfermagem: teorização, modelos e subsídios para prática. Goiânia(GO): $A B$; 2001. 
15 Oliveira LM, Evangelista RA. Sistematização da assistência de enfermagem (SAE): excelência no cuidado. Perquierere [periódico na internet] 2010 ago [acesso em 04 abr 2011]; 7(1): 83-8. Disponível em:

16 Pinto CAL. A importância do enfermeiro na central de material esterilizado. [acesso em 14 jun 2011]. Disponível em: http:/ / www.webartigos.com/articles/ 11 854/ / /AImportancia-do-Enfermeiro-n a - C e n t r a I-d e-M a terial-Esterilizado/paginal.html

17 Damas KCA, Munari DB, Siqueira KM. Cuidando do cuidador: reflexão sobre o aprendizado dessa habilidade. Rev Eletronica Enferm [periódico na internet] 2004 [acesso em 28 jul 2011]; 6(2): [aproximadamente $6 \mathrm{p}$ ]. Disponível em: http://revistas.ufg.br/index.php/fen/article/view /811/928

18 Martins MCFN. Humanização da assistência e 2003 maio [acesso em 28 jul 2011]; 8(5). Disponível formação do profissional de saúde. Psychiatry [online]. em http://www.polbr.med.br/ano03/artigo0503_1.p hp

19 Hermida PMV. Desvelando a implementação da sistematização da assistência de enfermagem. Rev Bras Enferm 2004; 57(6): 729-32.

20 Matté VM, Thofehm MB, Muniz RM. Opinião dos enfermeiros quanto à aplicabilidade do processo de enfermagem em unidade de tratamento intensivo. Revista Gaúcha de enfermagem, Porto Alegre (RS) 2001 jan; 22(1): 101-21.

21 Hermida PMV, Araújo IEM. Sistematização da assistência de enfermagem: subsídios para implantação. Rev Bras Enferm 2006 set/out; 59(5): 675-9.

22 Abrahão AL, Santos M, Leonardo SC, Souza RF. A dissonância entre formação do enfermeiro e sua prática de trabalho. Vidya [periódico na internet].
2010 jan/jun [acesso em 28 jul 2011]; 30(1): 53$60 . \quad$ Disponível em: http://sites.unifra.br/Portals/35/Artigos/2010/v ol1_1/dissonancia.pdf

23 Kletember DF, Mantovani MF, Lacerda MR. Entre a teoria e as práticas do cuidar: que caminho trilhar? Rev Bras Enferm 2003 [acesso em 28 jul 2011 1]. Disponível em: http://wwwl.capes.gov.br/ estudos/dados/2003/40001016/020/2003_020_ 40001016045P7_Programa.pdf

24 Mayer M, Costenaro RGS, Mota MS, Fossá MIT. A importância da comunicação organizacional na atuação da equipe multidisciplinar de saúde.

Encipecom [periódico na internet] [s.d.] [acesso em 27 jul 2011 ]. Disponível em: http:// encipecom.metodista.br/mediawiki/images/7/72 /GT1

25 Conselho Federal de Enfermagem (Br). Resolução COFEN 159/1993. [acesso em 08 jun 2011]. Disponível em: http://www.portaleducacao.com.br/enfermagem/ artigos/1970/ resolucao-cofen-159-1993dispoe-sobre-a-consulta-de-enfermagem.

26 Ortiz MCS. O movimento para (re) configuração sindical das enfermeiras no Brasil e no Peru: um estudo histórico comparado. Rio de Janeiro (RJ): EEAN; 2006.

27 Évora YDM. Sistema de informação: instrumento para tomada de decisão no exercício da gerência. Ciência da Informação [periódico na internet] 2004 [acesso em 29 jul 2011]; 33(1). Disponível em: http:// revista.ibict.br/index.php/ciinf/article/viewArticl e/62/56\#

28 Paulus Júnior A. Gerenciamento de recursos materiais em unidades de saúde. Rev Espaço para a saúde. [periódico na internet] 2005 dez [acesso em 29 jul 2011]; 7(1): 30-45. Disponível em: http://www.ccs.uel.br/espacoparasaude/v7n $1 / \mathrm{Ge}$ renciamento.pdf 
29 Gaíva MAM, Scochi CGS. Processo de trabalho em saúde e enfermagem em UTI neonatal. Rev Latinoam Enferm 2004 maio/jun; 12(3): 469-76.

30 Padilha MCS, Sobral VRS, Leite LMR, Peres MAA, Araújo AC. Enfermeira - a construção de um modelo a partir do discurso médico. Rev Esc Enf USP [periódico na internet]. 1997 [acesso em 03 ago 2011]; 31(3): 437-51. Disponível em:

http://www.ee.usp.br/reeusp/upload/pdf/390.pd $f$

31 Carvalho A, Muniz G, Marques AC, Sales N, Travassos V, Rios CT. Sistematização da assistência de enfermagem à cliente acometida por doença trofoblástica gestacional. $61^{\circ}$ Congresso
Brasileiro de Enfermagem; 2009 dez 7-10; Fortaleza [acesso em 03 a g o 2011]. Disponível em:

http:/ / www.abeneventos.com.br/anais_61 cben/fil es/01702.pdf

32 Novaczyk AB, Dias NS, Gaíva MAM. Atenção à saúde da criança na rede básica: análise de dissertações e teses de enfermagem. Rev Eletr Enf [periódico na internet]. 2008 [acesso em 03 ago 2011]; 10(4): 1124-37. Disponível em: http://www.fen.ufg.br/revista/v10/n4/v10n4a25. htm. 